Байкальский государственный университет, г. Иркутск, Российская Федерация

В. А. Оглоблин

Иркутский государственный университет путей сообщения, г. Иркутск, Российккая Федераиия

\title{
ОЦЕНКА РЕЗУЛЬТАТОВ КАДРОВОГО МЕНЕДЖМЕНТА В УСЛОВИЯХ ФУНКЦИОНИРОВАНИЯ СИСТЕМЫ УПРАВЛЕНИЯ ПЕРСОНАЛОМ
}

\begin{abstract}
АНнОтАЦия. В статье рассмотрены существующие точки зрения на определение понятий «управление кадрами», «управление персоналом», «управление человеческими ресурсами», «кадровый менеджмент». Выявлены цели деятельности каждого направления кадрового менеджмента. Определены методические подходы к оценке направлений кадрового менеджмента. Обосновано введение в систему кадрового менеджмента комплексной функции, ориентированной на выполнение стратегических целей деятельности предприятия. Раскрыто содержание понятия комплексной функции и определены требования к ее формированию. Построен алгоритм создания комплексной функции кадрового менеджмента. Разработана методика оценки эффективности выполнения комплексной функции кадрового менеджмента, основанная на исчислении интегральный коэффициент оценки эффективности выполнения кадрового менеджмента с учетом показателей результативности, экономической и социальной эффективности. Предложена система премирования работников кадровых служб в зависимости от результатов оценки эффективности выполнения комплексной функции кадрового менеджмента.

кЛючЕВЫЕ СЛОВА. Кадровый менеджмент; оценка эффективности комплексной функции кадрового менеджмента; комплексные функции кадрового менеджмента; результативность; экономическая эффективность; социальная эффективность.

ИНФОРМАЦИЯ О СТАТЬЕ. Дата поступления 4 апреля 2016 г.; дата принятия к печати 21 апреля 2016 г.; дата онлайн-размещения 31 мая 2016 г.
\end{abstract}

L. G. Sokolova Baikal State University, Irkutsk, Russian Federation V. A. Ogloblin Irkutsk State Railway Engineering University, Irkutsk, Russian Federation

\section{ASSESSING RESULTS OF PERSONNEL MANAGEMENT IN TERMS OF FUNCTIONING OF PERSONNEL MANAGEMENT SYSTEM}

\begin{abstract}
The article considers the existing viewpoints on defining the concepts «staff administration", "personnel management», «human resources management», "staff management» and identifies activity objectives for each direction of personnel management. It specifies methodical approaches to assessing the directions of personnel management. It substantiates introducing into the personnel management system a complex function oriented towards implementing strategic objectives of a company's activity, discloses the content of the complex function concept and specifies requirement to its building. The article builds up an algorithm of creating the complex function of personnel management, develops methods of assessing efficiency of personnel management complex function implementation based on calculating an integral coefficient for assessing efficiency of implementing personnel management in terms of indicators of performance, economic and social efficiency. It offers an incentive system for workers
\end{abstract}

(C) Л. Г. Соколова, В.А. Оглоблин, 2016

\section{Baikal Research Journal}


of personnel services depending on results of assessing efficiency of implementing the personnel management complex function.

KEYWORDS. Personnel management; assessing efficiency of personnel management complex function; complex functions of personnel management; performance; economic efficiency; social efficiency.

ARTICLE INFO. Received April 4, 2016; accepted April 21, 2016; available online May 31, 2016.

В научной экономической литературе существует множество определений понятия «управление людьми», причем редко делаются различия между уровнями управления и объектами исследования. В научной литературе различают понятия "управление кадрами», "управление персоналом», «управление человеческими ресурсами», характеризуемыми в основном по числу и составу исполняемых функций [1-4]. Проведенный анализ научного и эмпирического материала показал, что авторы зачастую используют термины «управление персоналом», «управление кадрами» и «управление человеческими ресурсами» как синонимы. С другой стороны, эти же авторы уделяют значительное внимание раскрытию содержания данных терминов. Так, В. Р. Веснин дает определение понятию «управление персоналом», но рядом в скобках указывает «управление человеческими ресурсами» [1]. Т. Ю. Базаров считает управление персоналом и управление человеческими ресурсами направлениями кадрового менеджмента и приводит различия между двумя этими направлениями [5]. По мнению Л. Г. Соколовой и Т. А. Поляковой, управление человеческими ресурсами отличается от управления кадрами [6].

Придерживаясь мнения большинства авторов, что понятия «управление кадрами», "управление персоналом», «управление человеческими ресурсами» являются направлениями кадрового менеджмента [3], выделим основные отличия рассматриваемых терминов с точки зрения реализации стратегических задач развития предприятия (табл. 1).

Таблица 1

Характеристика направлений кадрового менеджмента

\begin{tabular}{|l|l|l|l|}
\hline \multicolumn{1}{|c|}{ Понятие } & \multicolumn{1}{|c|}{ Характеристика функций } & $\begin{array}{c}\text { Наличие связи } \\
\text { функций кадрового } \\
\text { менеджмента со стра- } \\
\text { тегией организации }\end{array}$ & \multicolumn{1}{|l}{ Подход оценки } \\
\hline $\begin{array}{l}\text { Управление } \\
\text { кадрами }\end{array}$ & $\begin{array}{l}\text { Минимальный набор функций ка- } \\
\text { дровой службы }\end{array}$ & Явно не выражена & $\begin{array}{l}\text { Целевой (в рамках } \\
\text { функционала) }\end{array}$ \\
\hline $\begin{array}{l}\text { Управление } \\
\text { персоналом }\end{array}$ & $\begin{array}{l}\text { Жизненный или трудовой цикл } \\
\text { работника }\end{array}$ & $\begin{array}{l}\text { Фрагментарные } \\
\text { элементы }\end{array}$ & Процессный \\
\hline $\begin{array}{l}\text { Управление } \\
\text { человеческими } \\
\text { ресурсами }\end{array}$ & $\begin{array}{l}\text { Жизненный или трудовой цикл ра- } \\
\text { ботника, ориентированный на полу- } \\
\text { чение конкурентных преимуществ }\end{array}$ & Пряая зависимость & $\begin{array}{l}\text { Подход теории } \\
\text { систем }\end{array}$ \\
\hline
\end{tabular}

В своих исследованиях мы придерживаемся мнения о том, что управление кадрами ограничивается исполнением минимального набора функций жизненного цикла работников и ориентировано на конкретное выполнение узкоспециализированной задачи. Существующая система управления организацией является в основной степени функциональной, и кадровый менеджмент, таким образом, тоже осуществляется через функции. В связи с этим к выполнению и оценке деятельности кадровых служб возможно применять функциональный подход.

Управление персоналом предусматривает исполнение полного набора функций жизненного или трудового цикла работников, взаимозависимых друг от друга по результатам исполнения и нацеленных на выполнение стратегической цели пред-

\section{Baikal Research Journal}

электронный научный журнал Байкальского государственного университета 
приятия. По мнению некоторых авторов, функции управления персоналом необходимо рассматривать в соответствии с жизненным циклом работника - планирование потребности и движения, поиск, подбор, найм, адаптация, оценка, мотивация, обучение, развитие, ротация, релаксация и рекреация [6;7]. Однако есть и другой подход, где группы процессов выделяются в целях получения конкурентных преимуществ организацией [8]. Достоинства подхода управления персоналом по жизненному или трудовому циклу работника состоят в выделения процессов кадрового менеджмента большей объемности и легкости группировки, однако второй подход позволяет выделить такие процессы управления персоналом, которые в большей степени влияют на финансово-экономические результаты предприятия.

Применение в кадровом менеджменте системы управления персоналом позволяет использовать процессный подход к оценке кадрового менеджмента, суть которого заключается в применении оценочных критериев не по каждой отдельно выполненной функции, а по комплексу функций, сгруппированных на рассчитываемый результат деятельности предприятия или его структурного подразделения.

Отметим, что общепринятого перечня функций кадрового менеджмента и группировки его функций не существует. Каждый из авторов по-своему определяет список функций кадрового менеджмента $[1 ; 3 ; 5]$. Экспертные оценки позволили выявить, что каждое предприятие также произвольно устанавливает необходимые функции кадрового менеджмента и производит их группировку. Эта неоднородность в деятельности кадрового менеджмента не позволяет предложить универсальную методику оценки эффективности выполнения кадрового менеджмента и определения степени влияния его на результаты деятельности предприятия. С другой стороны, эта неопределенность открывает массу возможностей для такого рода исследований. Например, на достижение производственных целей предприятия влияет укомплектованность штата рабочих. Функция кадрового менеджмента «подбор персонала» позволяет получить список рабочих, которые по формальным признакам подходят для занятия свободных должностей. Однако выполнение этой функции не ведет к удовлетворению производственных потребностей организации в персонале. Функция кадрового менеджмента «найм персонала» не имеет смысла без выполнения перед ней функции «отбор персонала», и опять же выполнение этой функции не ведет к удовлетворению производственных потребностей организации в персонале, потому что неадаптированный персонал не может сразу после выхода на новую работу выполнять определенный объем производственного задания рабочего. Таким образом, перед выполнением функции кадрового менеджмента «адаптация персонала» должны быть обязательно выполнены функции кадрового менеджмента «подбор персонала», "отбор персонала» и «найм персонала» (рис. 1), и только после выполнения всех этих четырех функций кадрового менеджмента можно говорить о достижении производственных целей организации.

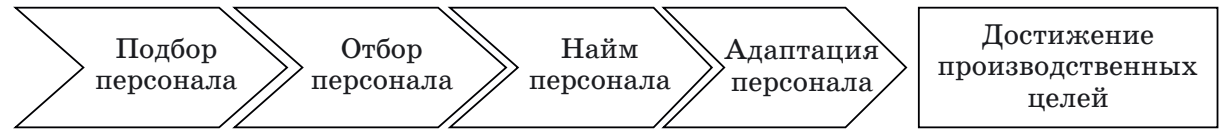

Рис. 1. Функции кадрового менеджмента, влияющие на достижение производственных иелей

Можно сделать вывод, что для достижения организационных целей предприятия необходимо выполнить несколько функций кадрового менеджмента. Следовательно, оценку результатов кадрового менеджмента целесообразно проводить не по выполнению каждой отдельной функции, а с позиции набора функций кадрового менеджмента, ориентированных на реализацию определенной цели предприятия.

\section{Baikal Research Journal}

электронный научный журнал Байкальского государственного университета 
При построении эффективной системы кадрового менеджмента необходимо выделять определенные наборы функций кадрового менеджмента или формировать комплексную функцию. Основными требованиями к формированию комплексной функции можно обозначить:

- выделенные функции должны существенно влиять на достижение целей организации;

- выделенные функции должны быть представлены набором функций кадрового менеджмента в соответствии с порядком жизненного цикла работника или получения конкурентного преимущества в области кадрового менеджмента;

- выделенные функции должны обязательно подвергаться оценке результатов их деятельности с точки зрения эффективности и достижения целей организации.

Таким образом, комплексная функция кадрового менеджмента представляет собой набор обычных функций, выполняемых в любом направлении кадрового менеджмента, результаты которой будут непосредственно измеримо влиять на достижение целей организации.

Для формирования комплексной функции кадрового менеджмента определим алгоритм ее компоновки. Целесообразно проводить данный процесс поэтапно. На первом этапе необходимо определить организационную цель деятельности предприятия, на которую будут направлены действия кадровой службы, далее сформулировать цель кадрового менеджмента, реализация которой сможет помочь в достижении поставленной организационной цели. Затем необходимо будет приступить к проектированию комплексной функции кадрового менеджмента, как связанного набора обычных функций. Последний этап - оценка степени достижения цели выполнения комплексной функции в связи с реализацией организационной цели (рис. 2).

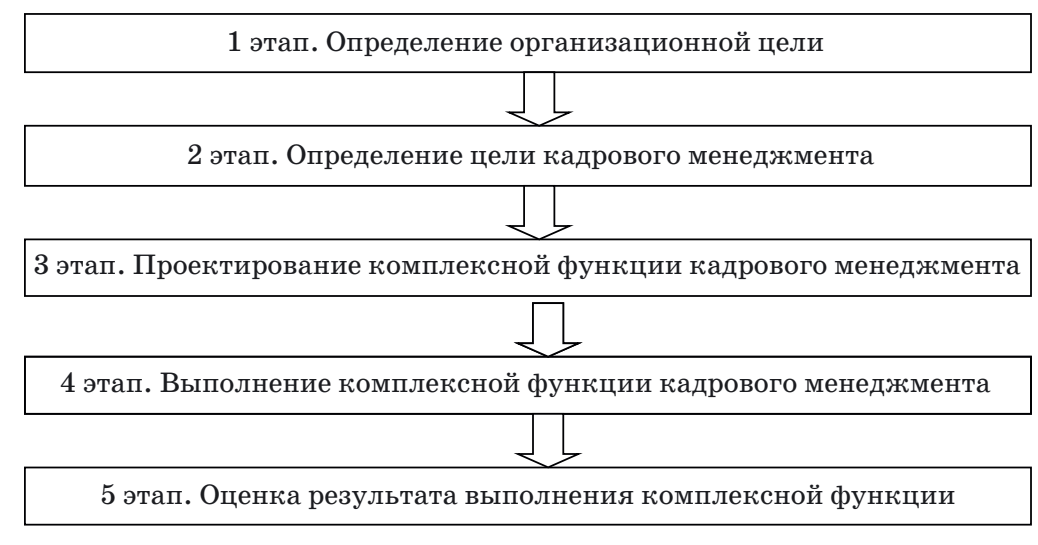

Рис. 2. Алгоритм создания комплексной функиии

Реализация механизма создания комплексных функций, ориентированных на конкретные цели деятельности предприятий, позволяет упростить работу кадрового работника, так как он будет в комплексе видеть цель проводимых мероприятий и знать методы оценки его работы.

Функционирование направления кадрового менеджмента - управление человеческими ресурсами, которое связано с высокоорганизованной системой управления персоналом и может применяться как на корпоративном уровне управления, так и на региональном. Управление человеческими ресурсами направлено на формирование такого состава кадров, который способен постоянно совершенствовать трудовой процесс и повышать производительность труда [9], поэтому каждая сформированная комплексная функция жизненного или трудового цикла работника при оценке

\section{Baikal Research Journal}

электронный научный журнал Байкальского государственного университета 
ее выполнения характеризуется преимуществами, получаемыми работником или организацией, при этом оценивается также ее влияние на формирование регионального рынка труда (рис. 3).

\begin{tabular}{|c|c|}
\hline Планирование потребности и движения & Соответствие квалификации \\
\hline Поиск, подбор, найм, адаптация & $\begin{array}{c}\text { требованиям занимаемой } \\
\text { должности }\end{array}$ \\
\hline Оценка, ротация, мотивация & $\begin{array}{c}\text { Повышение } \\
\text { производительности труда }\end{array}$ \\
\hline Оценка, обучение, развитие & $\begin{array}{c}\text { Повышение квалификации, } \\
\text { конкурентоспособность }\end{array}$ \\
\hline Оценка, ротация & $\begin{array}{c}\text { Освоение вторых и смежных } \\
\text { профессий }\end{array}$ \\
\hline Релаксация, рекреация, мотивация & $\begin{array}{c}\text { Совершенствование HR-бренда } \\
\text { организации }\end{array}$ \\
\hline
\end{tabular}

Рис. 3. Сравнение колплексных функиий жизненного иикла работника кадрового менеджмента и приобретения конкурентного преимущества

Изучение научной литературы показало различные позиции на процедуру оценки эффективности выполнения функций кадрового менеджмента. Многие исследователи пришли к выводу, что определение понятий «управление кадрами», «управление персоналом», «управление человеческими ресурсами» не имеет цели как таковой, и это не позволяет проводить процедуру оценки эффективности выполнения функций кадрового менеджмента [1; 10]. Однако в последних работах по управлению персоналом прослеживается противоположная тенденция [6; 11$]$.

Рассматривая способы оценки эффективности (целевой подход, подход теории систем и многопараметрический подход) [12], мы пришли к выводу, что при оценке эффективности управления персоналом многие исследователи (Б. М. Генкин [3], А. Я. Кибанов [13], Т. Д. Синявец [14], С. Н. Апенько [15], Ю. Г. Одегов [10]) в основном используют целевой подход. Тем не менее целевой подход не лишен недостатков:

- достижение цели не является легко измеримым, если организации не производят осязаемой продукции;

- организации предпринимают попытки реализовать несколько целей, а достижение одной из них зачастую препятствует или затрудняет выполнение других задач;

- само существование общего набора «официальных целей», на достижение которых направлены усилия всех членов, является спорным [16;17].

Использование целевого подхода при оценке комплексной функции будет не всегда оправдано. Например, предприятие устанавливает цель для оценки эффективности выполнения функции кадрового менеджмента «скорость закрытия вакансии» для комплексной функции «подбор, отбор, найм персонала». Данный критерий никак не учитывает испытательный срок вновь принятого, так как всегда есть вероятность, что новый сотрудник его не сможет пройти. Так что можно получить отличную оценку за выполнение функции «подбор, отбор и найм персонала», но организация не решит своих задач из-за того, что на этапе адаптации сотрудник уволится, поэтому для оценки эффективности комплексных функций кадрового менеджмента мы выбираем подход теории систем, т. е. установление универсальной оценки для цикла

\section{Baikal Research Journal}

электронный научный журнал Байкальского государственного университета

2016. T. 7 , № 3

ISSN 2411-6262

2016, vol. 7 , no. 3 
«вход-процесс-выход» комплексных функций кадрового менеджмента. Оценку предлагается ввести по следующим многоуровневым критериям: результативность; экономическая эффективность; социальная эффективность (табл. 2).

Таблица 2

Критерии оценки эффективности комплексных функций кадрового менеджмента

\begin{tabular}{|l|l|}
\hline \multicolumn{1}{|c|}{ Критериий } & \multicolumn{1}{c|}{ Описание } \\
\hline Результативность & Определяется количественными показателями \\
\hline Экономическая эффективность & Включает затраты и сроки выполнения комплексной функции \\
\hline Социальная эффективность & Отражает качество выполнения комплексной функции \\
\hline
\end{tabular}

Результативность выполнения комплексной функции кадрового менеджмента будем вычислять как степень реализации запланированной деятельности и достижения запланированных результатов по формуле

$$
P=\frac{\bar{I}}{I}
$$

где $P$ - результативность (от англ. - productivity); $\bar{I}$ - фактическое значение показателя; $I$ - плановое значение показателя.

Измеряться данный показатель будет в долях единицы. По сути, он является коэффициентом и чем ближе по значению к 1 , тем результативнее кадровый менеджмент на предприятии.

Сложнее ситуация с экономической эффективностью, она должна быть регулируемой, т. е. это означает, что бизнес может сам определять соотношение «качество - цена». Для подсчета стоимости выполнения комплексной функции кадрового менеджмента можно использовать уже апробированную методику, применяемую в проектной деятельности:

$$
Ц=\sum P N_{u с n} N_{\text {чән }} 3 n_{c p},
$$

где $Ц$ - стоимость выполнения комплексной функции кадрового менеджмента; $P$ - вид выполняемой работы; $N_{u c n}-$ количество исполнителей; $N_{\text {чдн }}-$ количество человеко-дней; $3 n_{c p}-$ средняя оплата труда за 1 день.

Относительно полезных результатов можно сказать, что они будут складываться из двух равноправных частей: стоимость мероприятий, которые необходимо предпринимать, если выполнение комплексной функции кадрового менеджмента была осуществлено некачественно (например, стоимость повторного подбора, отбоpa, найма и адаптации в случае увольнения только что устроившегося на работу сотрудника) и рост производительности труда в денежном выражении. Причем, если стоимость мероприятий, которые необходимо предпринимать, если выполнение комплексной функции кадрового менеджмента была произведено некачественно, рассчитывается индивидуально в каждом случае, то рост производительности труда в денежном выражении высчитывается для всех случаев оказания выполнения комплексных функций кадрового менеджмента (если невозможно посчитать рост производительности труда в денежном выражении для выполнения отдельной комплексной функции кадрового менеджмента):

$$
\ni_{\phi}=\frac{\sum Ц_{m}+\Delta \Pi}{\sum Ц},
$$

где $\vartheta_{\phi}-$ экономическая эффективность деятельности кадровой службы за отчетный период; $\Sigma Ц_{n}-$ сумма стоимости повторно выполненных комплексных функций кадровой службой; $\Delta \Pi_{m}$ - изменение производительности труда в стоимостном выражении; $\Sigma Ц$ - сумма стоимости выполненных комплексных функций кадровой службой.

\section{Baikal Research Journal}


Можно еще учесть упущенную выгоду в результате оказания некачественно выполненных комплексных функций кадрового менеджмента.

Социальную эффективность выполнения комплексной функции будем вычислять как степень отклонения запланированного значения уровня качества и достижения фактического значения уровня качества по формуле

$$
Q=\frac{\bar{I}}{I},
$$

где $Q$ - социальная эффективность / качество (от англ. quality); $I$ - плановое значение показателя буквой; $\bar{I}-$ фактическое значение показателя.

Измеряться данный показатель будет в долях единицы и, по сути, является коэффициентом (чем он ближе по значению к 1 , тем качественнее кадровый менеджмент на предприятии).

Далее предлагаем простым суммированием всех упомянутых коэффициентов определить интегральный коэффициент оценки эффективности выполнения кадрового менеджмента

$$
K_{I}=P+\vartheta_{\phi}+Q,
$$

где $K_{I}$ - интегральный коэффициент оценки эффективности выполнения кадрового менеджмента; $P$ - результативность (от англ. productivity); $Э_{\phi}$ - экономическая эффективность деятельности кадровой службы за отчетный период; $Q-$ социальная эффективность.

В целях мотивации работников кадровых служб предлагаем ввести систему премирования в зависимости от результатов оценки эффективности выполнения кадрового менеджмента. Сущность системы состоит в том, что размер премии, начисляемой работнику кадровой службы, ставится в прямую зависимость от результатов труда обслуживаемых им подразделений при выполнении комплексной функции.

Размер премии для исполнителя комплексной функции кадрового менеджмента вычисляется следующим образом:

$$
B=O_{\partial} \kappa T У N_{f} \Delta \Pi_{m},
$$

где $B$ - размер премии (от англ. bonus); $O_{\partial}$ - размер должностного оклада; $K T У-$ средний коэффициент трудового участия в выполнении комплексных функций кадрового менеджмента; $N_{f}$ - количество выполненных комплексных функций кадрового менеджмента; $\Delta \Pi_{m}-$ изменение производительности труда в стоимостном выражении.

Размер премии для руководителя кадровой службы рассчитывается по формуле

$$
B=O_{\partial} K_{I},
$$

где $O_{\partial}-$ размер должностного оклада; $K_{I}-$ интегральный коэффициент оценки эффективности выполнения кадрового менеджмента.

Таким образом, объединив обычные функции кадрового менеджмента в несколько комплексных функций, получаем возможность влиять на реализацию стратегических целей развития предприятия путем оценки эффективности их исполнения, используя для этого критерии результативности, экономической и социальной эффективности.

\section{Список использованной литературы}

1. Веснин В. Р. Управление человеческими ресурсами. Теория и практика : учебник / В. Р. Веснин. - М. : Проспект, 2015. - 688 с.

2. Соколова Л. Г. Управление человеческими ресурсами в муниципальной службе : модуль для повышения квалификации муниципальных служащих / Л. Г. Соколова. - Иркутск : Изд-во БГУЭП, 2009. - 209 с.

\section{Baikal Research Journal}


3. Генкин Б. М. Экономика и социология труда : учебник / Б. М. Генкин. - 7-е изд., доп. - М. : Норма, 2007. - 448 c.

4. Управление человеческими ресурсами : учеб. для бакалавров / под ред. И. А. Максимцева, Н. А. Горелова. - 2-е изд., перераб. и доп. - М. : Юрайт, 2014. - 526 с. - (Бакалавр. Углубленный курс).

5. Управление персоналом : учебник / под ред. Т. Ю. Базарова, Б. Л. Еремина. — 2-е изд., перераб. и доп. - М. : Юнити, 2002. - 560 с.

6. Управление персоналом : учеб.-метод. комплекс / сост. Л. Г. Соколова, Т. А. Полякова. - Иркутск : Изд-во БГУЭП, 2006. - 55 с.

7. Соколова М. И. Управление человеческими ресурсами : учебник / М. И. Соколова, А. Г. Дементьева. - М. : ТК Велби : Проспект, 2006. - 240 с.

8. Оглоблин В. А. Подход к классификации процессов управления человеческими ресурсами с точки зрения повышения конкурентоспособности организации / В. А. Оглоблин // Роль инноваций в трансформации современной науки : материалы Междунар. науч.-практ. конф. Казань, 20 ноября 2015 г. - Казань : Аэтерна, 2015. - С. 200-203.

9. Соколова Л. Г. Методология расчета производительности управленческого труда / Л. Г. Соколова / Известия Иркутской государственной экономической академии. - 2016. T. 26, № 2. — C. 213-219. — DOI : 10.17150/1993-3541.2016.26(2).213-219.

10. Одегов Ю. Г. Управление персоналом: оценка эффективности : учеб. пособие / Ю. Г. Одегов, Л. В. Карташова. - М. : Экзамен, 2002. - 256 с.

11. Армстронг М. Стратегическое управление человеческими ресурсами : пер. с англ. / Майкл Армстронг. - М. : Инфра-М, 2002. - 328 с.

12. Гибсон Дж. Л. Организации: поведение, структура, процессы : пер. с англ. / Дж. Л. Гистон, Д. М. Иванцевич, Д. Х. Донелли, мл. - 8-е изд. - М. : Инфра-М, 2000. - 662 с.

13. Проект профессионального стандарта «Руководитель подразделения (службы) управления персоналом организации» / под ред. А. Я. Кибанова. - М. : Гос. ун-т управления, 2015. - 126 c.

14. Синявец Т. Д. Теоретические подходы к определению эффективности управления персоналом / Т. Д. Синявец // Вестник Воронежского государственного университета. Сер.: Экономика и управление. - 2005. - № 1. - С. 90-96.

15. Апенько С. Н. Эффективность системы оценки персонала / С. Н. Апенько // Человек и труд. - 2003. - № 10. - С. 73-74.

16. Harrison Frank E. Management and Organization / Frank E. Harrison. - Boston : Houghton Mifflin, 1978. - 555 p.

17. Connolly Terry. Organizational Effectveness: A Multiple-Constituence Approac / Terry Connolly, Edward J. Conion, Stuart Jay Deutsch / / Academy of Management Review. — 1980. Vol. 5. - P. 212-217.

\section{References}

1. Vesnin V. R. Upravlenie chelovecheskimi resursami. Teoriya i praktika [Human resources management. Theory and practice]. Moscow, Prospekt Publ., 2015. 688 p.

2. Sokolova L. G. Upravlenie chelovecheskimi resursami v munitsipalnoi sluzhbe [Human resources management in municipal service]. Irkutsk, Baikal State University of Economics and Law Publ., 2009. 209 p.

3. Genkin B. M. Ekonomika $i$ sotsiologiya truda [Economy and sociology of labor]. $7^{\text {th }}$ ed. Moscow, Norma Publ., 2007. 448 p.

4. Maksimtseva I. A., Gorelova N. A. (eds). Upravlenie chelovecheskimi resursami [Human resources management]. $2^{\text {nd }}$ ed. Moscow, Yurait Publ., 2014. 526 p.

5. Sokolova M. I., Dement'eva A. G. Upravlenie chelovecheskimi resursami [Human resources management]. Moscow, TK Velbi Publ., Prospekt Publ., 2006. 240 p.

6. Bazarov T. Yu., Eremin B. L. (ed.) Upravlenie personalom [Human resources management]. $2^{\text {nd }}$ ed. Moscow, Yuniti Publ., 2002. 560 p.

7. Sokolova L. G., Polyakova T. A. (eds). Upravlenie personalom: uchebno-metodicheskii kom pleks [Personnel Management]. Irkutsk, Baikal State University of Economics and Law Publ., 2006. $55 \mathrm{p}$.

8. Ogloblin V. A. An approach to classification of processes of human resources management in term of increasing competitiveness of organizations. Rol' innovatsii $v$ transformatsii sovremennoi

\section{Baikal Research Journal}


nauki. Materialy mezhdunarodnoi nauchno-prakticheskoi konferentsii. Kazan', 20 noyabrya Role of innovations in transformation of modern science. Materials of International Research Conference. Kazan', November 20, 2015]. Kazan', Aeterna Publ., 2015, pp. 200-203. (In Russian).

9. Sokolova L. G. Calculation methodology for the management performance evaluation. $I z$ vestiya Irkutskoi gosudarstvennoi ekonomicheskoi akademii = Bulletin of Irkutsk State Economics Academy, 2016, vol. 26, no. 2, pp. 213-219. DOI: 10.17150/1993-3541.2016.26(2).213-219. (In Russian).

10. Odegov Yu. G., Kartashova L. V. Upravlenie personalom: otsenka effektivnosti [Personnel management: assessment of efficiency]. Moscow, Ekzamen Publ., 2002. 256 p.

11. Armstrong Michael. Strategic human resource management. 4 th ed. New York, Kogan Page, 2000. 276 p. (Russ. ed.: Armstrong Michael. Strategicheskoe upravlenie chelovecheskimi resursami. Moscow, Infra-M Publ., 2002. 328 p.).

12. Gibson Dzh. L., Ivantsevich D. M., Donelli D. Kh. ml. Organizatsii: povedenie, struktura, protsessy [Organizations: behviour, structure, processes]. $8^{\text {th }}$ ed. Moscow, Infra-M Publ., 2000. $662 \mathrm{p}$.

13. Kibanov A. Ya. (ed.). Proekt professional'nogo standarta "Rukovoditel' podrazdeleniya (sluzhby) upravleniya personalom organizatsii» [Project of professional standard «Head of Department (Service) of organization's personnel management»]. Moscow, State University of Management Publ., 2015. 126 p.

14. Sinyavets T. D. Theoretical approaches to defining personnel management efficiency. Vestnik Voronezhskogo gosudarstvennogo universiteta. Seriya: Ekonomika $i$ upravlenie $=$ The Herald of Voronezh State University. Economics and Management Series, 2005, no. 1, pp. 90-96. (In Russian).

15. Apen'ko S. N. Efficiency of personnel assessment system. Chelovek $i$ trud $=$ Man and Labour, 2003, no. 10, pp. 73-74. (In Russian).

16. Harrison Frank E. Management and Organization. Boston, Houghton Mifflin, 1978. 555 p.

17. Connolly Terry, Conion Edward J., Deutsch Stuart Jay. Organizational effectveness: A multiple-constituence approac. Academy of Management Review, 1980, vol. 5, pp. 212-217.

\section{Информация об авторах}

Соколова Лариса Георгиевна - доктор экономических наук, профессор, кафедра экономики и государственного управления, Байкальский государственный университет, 664003, г. Иркутск, ул. Ленина, 11, e-mail: sokolova-lg@yandex.ru.

Оглоблин Владимир Александрович - кафедра менеджмента, Иркутский государственный университет путей сообщения, 664074, г. Иркутск, ул. Чернышевского, 15, e-mail: ogloblinva@mail.ru.

\section{Authors}

Larisa G. Sokolova - Doctor habil. (Economics), Professor, Chair of Economics and Public Administration, Baikal State University, 11 Lenin St., 664003, Irkutsk, Russian Federation; e-mail: sokolova-lg@yandex.ru.

Vladimir A. Ogloblin - Senior Lecturer, Irkutsk State Railway Engineering University, 15 Chernyshesky St., 664074, Irkutsk, Russian Federation; e-mail: ogloblinva@mail.ru.

\section{Библиографическое описание статьи}

Соколова Л. Г. Оценка результатов кадрового менеджмента в условиях функционирования системы управления персоналом / Л. Г. Соколова, В. А. Оглоблин // Baikal Research Journal. — 2016. — T. 7, № 3. - DOI : 10.17150/2411-6262.2016.7(3).18.

\section{Reference to article}

Sokolova L. G., Ogloblin V. A. Assessing results of personnel management in terms of functioning of personnel management system. Baikal Research Journal, 2016, vol. 7, no. 3. DOI : 10.17150/2411-6262.2016.7(3).18. (In Russian).

\section{Baikal Research Journal}

